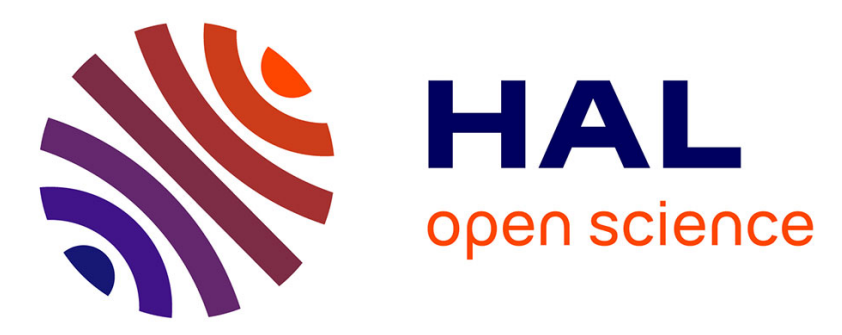

\title{
Semi-ab initio calculations of superposition model and crystal field parameters for Co ions using the exchange charge model
}

\author{
M.G. Brik, Y.-Y. Yau-Yuen Yeung
}

\section{- To cite this version:}

M.G. Brik, Y.-Y. Yau-Yuen Yeung. Semi-ab initio calculations of superposition model and crystal field parameters for Co ions using the exchange charge model. Journal of Physics and Chemistry of Solids, 2009, 69 (10), pp.2401. 10.1016/j.jpcs.2008.04.032 . hal-00573080

\section{HAL Id: hal-00573080 \\ https://hal.science/hal-00573080}

Submitted on 3 Mar 2011

HAL is a multi-disciplinary open access archive for the deposit and dissemination of scientific research documents, whether they are published or not. The documents may come from teaching and research institutions in France or abroad, or from public or private research centers.
L'archive ouverte pluridisciplinaire HAL, est destinée au dépôt et à la diffusion de documents scientifiques de niveau recherche, publiés ou non, émanant des établissements d'enseignement et de recherche français ou étrangers, des laboratoires publics ou privés. 


\section{Author's Accepted Manuscript}

Semi-ab initio calculations of superposition model and crystal field parameters for $\mathrm{Co}^{2+}$ ions using the exchange charge model

M.G. Brik, Yau-yuen Yeung

PII: $\quad$ S0022-3697(08)00143-1

DOI: doi:10.1016/j.jpcs.2008.04.032

Reference: PCS 5471

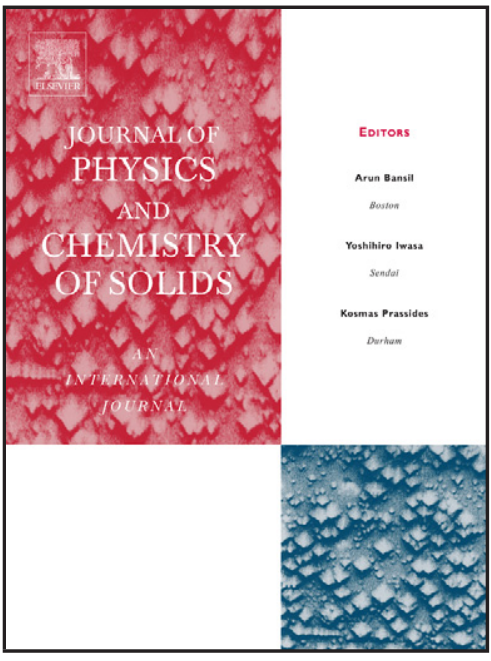

www.elsevier.com/locate/jpcs

To appear in: $\quad$ Journal of Physics and Chemistry of Solids

Received date: 9 January 2008

Revised date: $\quad 18$ February 2008

Accepted date: 10 April 2008

Cite this article as: M.G. Brik and Yau-yuen Yeung, Semi-ab initio calculations of superposition model and crystal field parameters for $\mathrm{Co}^{2+}$ ions using the exchange charge model, Journal of Physics and Chemistry of Solids (2008), doi:10.1016/j.jpcs.2008.04.032

This is a PDF file of an unedited manuscript that has been accepted for publication. As a service to our customers we are providing this early version of the manuscript. The manuscript will undergo copyediting, typesetting, and review of the resulting galley proof before it is published in its final citable form. Please note that during the production process errors may be discovered which could affect the content, and all legal disclaimers that apply to the journal pertain. 


\title{
Semi-ab initio calculations of superposition model and crystal field parameters for $\mathrm{Co}^{2+}$ ions using the exchange charge model
}

\author{
M.G. BRIK ${ }^{1, *}$ and Yau-yuen YEUNG ${ }^{2}$ \\ ${ }^{1}$ Institute of Physics, University of Tartu, Riia 142, Tartu 51014, Estonia \\ ${ }^{2}$ Department of Mathematics, Science, Social Sciences and Technology, The Hong Kong \\ Institute of Education, 10 Lo Ping Road, Tai Po, New Territories, Hong Kong, China
}

\begin{abstract}
This paper attempts for the first time to establish a reliable linkage between the two wellknown and independent models of crystal field (CF), namely the exchange charge (ECM) and superposition models (SM). Our approach aims to show that the SM parameters can be reliably extracted from the distance dependence of the $\mathrm{CF}$ invariants for $\mathrm{Co}^{2+}$ as derived from the ECM through some semi-ab initio calculations which involved a single fitting parameter and a set of newly constructed procedures. Complete sets of the numerical values of SM parameters $\bar{B}_{k}$ and $t_{k}$ for $\mathrm{Co}^{2+}$ in its own host lattices of $\mathrm{Li}_{2} \mathrm{Co}_{3}\left(\mathrm{SeO}_{3}\right)_{4}, \mathrm{CoSO}_{4} \cdot \mathrm{H}_{2} \mathrm{O}$, $\mathrm{CoSeO}_{4} \cdot \mathrm{H}_{2} \mathrm{O}$, and $\mathrm{Co}(\mathrm{OH})_{2}$ are obtained and they are found to be around $13,000-16,000 \mathrm{~cm}^{-}$ ${ }^{1}$ for $\bar{B}_{2}, 4,100-5,700 \mathrm{~cm}^{-1}$ for $\bar{B}_{4}, 4.1-5.0$ for $t_{2}$ and $6.2-6.5$ for $t_{4}$. The present results generally agree with but should be much better than those incomplete sets of results found by previous researchers using the conventional fitting approach. Plausible explanations for some noticeable discrepancies are also discussed together with the effects of different $\mathrm{CF}$ contributions on values of the SM parameters.
\end{abstract}

\section{Key words: A. Optical materials; D. Crystal fields; D. Optical properties}

\section{Introduction}

It is a well established fact that the energy levels of any ion with an unfilled electron shell are split by the crystal field, if this ion is placed into a crystal or a glass (Refs. 1-6, and references therein). Since the pioneering paper by Bethe ${ }^{1}$, several models of crystal field have been developed and are now actively being used worldwide by many researchers. All of them have a common starting point, namely the Hamiltonian of the ion under consideration, (as a rule, with $d$ or $f$ open shell; in what follows this ion will be referred to as a central ion) can be

\footnotetext{
${ }^{*}$ E-mail: $\underline{\text { brik@,fi.tartu.ee }}$
} 
represented as a linear combination of suitably normalized tensor operators $O_{p}^{k}$ in the following form:

$$
H=\sum_{p=2}^{2 l} \sum_{k=-p}^{p} B_{p}^{k} O_{p}^{k},
$$

where $B_{p}^{k}$ has dimensions of energy and stands for the crystal field parameters (CFP), and $l$ is the orbital momentum quantum number of the unfilled shell electrons. The $O_{p}^{k}$ operators act upon the angular parts of the central ion wave functions. The $B_{p}^{k}$ parameters contain all information about the crystal properties, such as geometry of the surrounding ions, chemical bond lengths and angles. They are also related to the electron density of the central ion. The structure of the Hamiltonian (1) or, in other words, the number of non-zero CFPs depends on the symmetry of the considered complex and increases by lowering the symmetry.

Very often the $B_{p}^{k}$ parameters are treated as the fitting parameters defined by matching the calculated and observed energy level schemes. In this case, initial assumptions about the point symmetry of the cluster should be introduced before fitting. Though such an approach allows for getting very good agreement between the calculated and observed energy levels, employment of a great number of fitting parameters (which can be as great as 14 for $d$-ions and 27 for $f$-ions) makes the fitting procedure rather complicated.

However, there are several models of crystal field which allows for direct calculation or estimation of the numerical values of CFP's. In the next section two such models used in the present paper - superposition model $(\mathrm{SM})^{7}$ and exchange charge model $(\mathrm{ECM})^{8}$ will be described briefly. The main goal of the present study is to establish a feasible way to extract the values of the SM intrinsic parameters for $\mathrm{Co}^{2+}$ using the values of CFP obtained within the framework of ECM and to re-examine the plausible form of the distance dependence of the SM intrinsic parameters. The present approach is very different from the traditional approach which fits the SM parameters to the empirical CFP. The latter approach is often found to be unfeasible in many physical systems because of rather limited or an incomplete set of CFP derived from the experimental energy levels. This is especially true for the spectra of $3 \mathrm{~d}$ ions, when the number of the non-zero CFP in the low-symmetry centers may be greater than the number of the well-detected energy levels. 


\section{Superposition model and exchange charge model of crystal field.}

\subsection{Superposition model}

Since the SM was introduced by Newman and his co-workers ${ }^{7,9}$ to successfully analyse the CFP of lanthanide ions in various garnets and other crystal systems ${ }^{10}$, its equation and formalism had been widely extended to model the spin-Hamiltonian parameters (SHP) for the zero-field splittings of the ground ${ }^{8} \mathrm{~S}_{7 / 2}$ state of the $4 \mathrm{f}^{7}\left(\mathrm{Gd}^{3+}\right.$ and $\left.\mathrm{Eu}^{2+}\right)$ ions or ground ${ }^{6} \mathrm{~S}_{5 / 2}$ state of $3 \mathrm{~d}^{5}\left(\mathrm{Fe}^{3+}\right.$ and $\left.\mathrm{Mn}^{2+}\right)$ ions ${ }^{11-13}$, even though the contributing mechanisms to SHP are substantially different from those of CFP. For analyzing the crystal field splittings of the $3 \mathrm{~d}$ transition-metal ions, the examples of SM application were relatively fewer ${ }^{14-16}$ because of the rather limited number or incomplete set of CFP derived from some experimental energy levels of which their states are often poorly determined or identified. Since the successful demonstration $^{17}$ of the effective use of SM for modeling the impurity-induced local distortion

of $\mathrm{Eu}^{2+}$ doped in various alkali halides, another major application of SM is related to the study of local distortion for the doping of transition-metal ions in various crystal lattices. ${ }^{12,16}$ However, it must be noted that a number of researchers have held or overlooked a common fallacy in this area of study because of (i) their adoption of an oversimplified local distortion model and (ii) fitting too many (i.e. over fitting) distortion parameters to the limited number of experimental data via the SM parameterization.

For analyzing the CFP of $3 \mathrm{~d}$ ions, we shall adopt the approximate assumptions of SM that the major interactions between the transition-metal ion and its neighbouring ligands are cylindrically symmetric (i.e. characterized by the $\mathrm{C}_{\infty \mathrm{v}}$ point symmetry group) and independent. Hence, the CFP can be written as linear sum of the crystal field contributions from individual ligand $\mathrm{L}$ located at the polar position $\left(R_{L}, \theta_{L}, \phi_{L}\right)$ with respect to a chosen coordinate frame:

$$
B_{p}^{k}=\sum_{L} \bar{B}_{k}\left(R_{L}\right) \cdot G_{k, p}\left(\theta_{L}, \phi_{L}\right)
$$

where the coordination factors $G_{k, p}\left(\theta_{L}, \phi_{L}\right)$ are explicitly given in Table 5.1 of Ref. 9. For the SM intrinsic parameters $\bar{B}_{k}(R)$, their distance dependence is often assumed to follow a power-law form:

$$
\bar{B}_{k}(R)=\bar{B}_{k}\left(R_{0}\right) \cdot\left(R_{0} / R\right)^{t_{k}}
$$

where the power-law exponents $t_{k}>0(k=2,4$ for $3 d$ ions and 2, 4, 6 for $4 \mathrm{f}$ ions $)$ are treated as adjustable parameters and their values are usually greater than the values of $k+1$ (as predicted by the point charge electrostatic model) because of the dominant (short-range) overlap and covalency contribution to the crystal field in the transition-metal ions. However, 
Levin and Cherepanov ${ }^{18}$ proposed an alternative two-power law formula for the distance dependence of $\bar{B}_{k}(R)$, but this was commented by Newman and $\mathrm{Ng}^{9}$ to be phenomenologically no better or worse than using the conventional SM parameterization which involves just two parameters $\bar{B}_{k}\left(R_{0}\right)$ and $\mathrm{t}_{\mathrm{k}}$ for each rank of crystal field. Newman and $\mathrm{Ng}^{7}$ have remarked that the power-law expression (3), in fact, has no special merit and because of the narrow range of $\mathrm{R}_{\mathrm{L}}$ for the experimental data, it is empirically indistinguishable from the exponential form:

$$
\bar{B}_{k}(R)=\bar{B}_{k}\left(R_{0}\right) \cdot e^{-\mu_{k} \cdot R},
$$

While there had been many extensive applications of the SM in lanthanide $\left(4 \mathrm{f}^{\mathrm{n}}\right)$ crystal field $^{7}$, rather few papers were published on the "proper" use of SM in the crystal field of transition metal $\left(3 \mathrm{~d}^{\mathrm{n}}\right)$ ions. The most noticeable work was performed by Yeung and Newman ${ }^{19}$ on the first successful use of the SM to simultaneously analyze strain-induced zero field splittings and optical spectra of $\mathrm{Cr}^{3+}: \mathrm{Al}_{2} \mathrm{O}_{3}$ system which clarified the past serious "misuse" of $\mathrm{SM}$ by various researchers. The approach was further extended to study other oxide systems (especially some ions located at very low site-symmetry) by Yeung and his co-workers ${ }^{16,20-22}$, yielding some empirical estimates of SM parameters for the $\mathrm{Cr}^{3+}$ ion. On the other hand, Wildner, Giester and Andrut ${ }^{23-26}$ had started from late 1990s to make a systematic extraction of the SM parameters for $\mathrm{Co}^{2+}$ ion from the electronic absorption spectra of several oxide crystals containing $\mathrm{Co}^{2+}$ ions in their original host lattices. However, there still lacks some reliable ab initio calculations for the CFP of $\mathrm{Co}^{2+}$ ion in the corresponding oxide crystals for triangulation with the empirical results. Therefore, it would be scientifically meaningful to make numerical calculations through the exchange charge model (as described in the next section) to (a) predict the values of the intrinsic parameters $\bar{B}_{k}\left(R_{0}\right)$ for $\mathrm{Co}^{2+}$ located in some oxygen-ligand crystals and to (b) critically examine and determine the distance dependence of the intrinsic parameters for the $\mathrm{Co}^{2+}$ ion located in those physical systems.

\subsection{Exchange charge model}

In the exchange charge model (ECM) framework, the energy levels of a $3 d$ impurity ion in a crystal field (CF) of an arbitrary symmetry are represented by the eigenvalues of crystal field Hamiltonian from Eq. (1). ${ }^{8} O_{p}^{k}$ are the suitably chosen linear combinations of the irreducible tensor operators acting on the angular parts of the $3 d$ ion wave functions, and $B_{p}^{k}$ 
are the crystal field parameters (CFP) containing all information about geometrical structure of an impurity center. The basic assumption of the ECM is that these parameters can be written as a sum of two terms ${ }^{8}$ :

$$
B_{p}^{k}=B_{p, q}^{k}+B_{p, S}^{k}
$$

The first contribution is due to the electrostatic interaction between the valence electrons of an impurity ion and crystal lattice ions (which, at this point, are treated as the point charges only, without taking into account their electronic structure), and the second one is proportional to the overlap of the wave functions of an impurity ion and ligands. This term includes all effects of the covalent bond formation between an impurity ion and ligands. Inclusion of these effects significantly improves agreement between the calculated and experimentally observed energy levels. Analytical expressions for calculating both contributions in the case of $3 d$-ion are as follows ${ }^{8}$ :

$$
\begin{gathered}
B_{p, q}^{k}=-K_{p}^{k} e^{2}\left\langle r^{p}\right\rangle \sum_{i} q_{i} \frac{V_{p}^{k}\left(\theta_{i}, \varphi_{i}\right)}{R_{i}^{p+1}}, \\
B_{p, S}^{k}=K_{p}^{k} e^{2} \frac{2(2 p+1)}{5} \sum_{i}\left(G_{s} S(s)_{i}{ }^{2}+G_{\sigma} S(\sigma)_{i}{ }^{2}+\gamma_{p} G_{\pi} S(\pi)_{i}{ }^{2}\right) \frac{V_{p}^{k}\left(\theta_{i}, \varphi_{i}\right)}{R_{i}} .
\end{gathered}
$$

The sums are carried out over lattice ions numbered by symbol $i$ with charges $q_{i} ; R_{i}, \theta_{i}, \varphi_{i}$ are the spherical coordinates of the $i$-th ion of crystal lattice in the system of reference centered at the impurity ion. As reported in one of our previous paper (see Ref.[35]), our detailed analysis showed that the rank $2\left(\mathrm{~B}_{2 \mathrm{q}}\right)$ and rank $4\left(\mathrm{~B}_{4 \mathrm{q}}\right)$ CF parameters of $\mathrm{Ni}^{2+}: \mathrm{MgAl}_{2} \mathrm{O}_{4}$ would require about 1500 and 500 ions to get their values stabilized, respectively. For our present 4 crystals, we have a much larger size of cluster which ranges from 24,616 to 53,385 ions with ions truncated at a given radial distance (of around 44.99 to $50.00 \AA$ ) to preserve the proper local site-symmetry of the $\mathrm{Co}^{2+}$ ion which is placed at the centre of this cluster. A large cluster is especially essential for the accurate calculation of the long-range electrostatic contribution as given by Eq. (6) while it is much less crucial for the short-range exchange contribution given by Eq.(7).

The averaged values $\left\langle r^{p}\right\rangle$ of $p$-th power of the radial coordinate of electrons from the impurity ion unfilled shell are given in Ref. 27, for example, or can be easily calculated numerically using the corresponding wave functions. The values of the numerical factors $K_{p}^{k}, \gamma_{p}$, expressions for the polynomials $V_{p}^{k}$ and definitions of the operators $O_{p}^{k}$ can be 
found in Ref. 8. The overlap integrals between the $d$-functions of the central ion and $p$ - and $s$ functions of the ligands are denoted by $S(s), S(\sigma), S(\pi)$ (they correspond to the following integrals (in $\left\langle l m \mid l^{\prime} m^{\prime}\right\rangle$ notation): $\left.S(s)=\langle d 0 \mid s 0\rangle, S(\sigma)=\langle d 0 \mid p 0\rangle, S(\pi)=\langle d 1 \mid p 1\rangle\right) . \mathrm{G}_{\mathrm{s}}, \mathrm{G}_{\sigma}$, and $\mathrm{G}_{\pi}$ are dimensionless adjustable parameters of the model, which are determined from the positions of the first three absorption bands. For the sake of simplicity, they can be assumed to be equal to each other: $G_{s}=G_{\sigma}=G_{\pi}=G$ (in this case only, the first absorption band is required to determine the value of $G$, while employing three fitting parameters would require at least three absorption bands detected precisely in the experimental spectra). We restrict ourselves by this simplified model. As will be shown later, even one fitting parameter is sufficient to get reasonable agreement between positions of the calculated and experimentally detected energy levels.

Previously, the ECM has been successfully applied for calculations of the energy levels of both rare earth ${ }^{8,28-32}$ and transition metal ions ${ }^{33-36}$ in different hosts, and in analysis of the electron-phonon coupling. ${ }^{37-40}$

\section{Short description of the studied crystals}

All of the four crystals considered in the present work $\left(\mathrm{Li}_{2} \mathrm{Co}_{3}\left(\mathrm{SeO}_{3}\right)_{4}, \mathrm{CoSO}_{4} \cdot \mathrm{H}_{2} \mathrm{O}\right.$, $\left.\mathrm{CoSeO}_{4} \cdot \mathrm{H}_{2} \mathrm{O}, \mathrm{Co}(\mathrm{OH})_{2}\right)$ contain $\mathrm{Co}^{2+}$ ion as a part of crystal lattice. Such a choice of crystals eliminates all phenomena related to the lattice distortions after doping and allows for a direct use of the crystal structure data without introducing any corrections to the ionic positions.

Three crystals $\left(\mathrm{Li}_{2} \mathrm{Co}_{3}\left(\mathrm{SeO}_{3}\right)_{4}, \mathrm{CoSO}_{4} \cdot \mathrm{H}_{2} \mathrm{O}, \mathrm{CoSeO}_{4} \cdot \mathrm{H}_{2} \mathrm{O}\right)$ have monoclinic crystal structures, whereas the remaining one $\left.\left(\mathrm{Co}(\mathrm{OH})_{2}\right)\right)$ has a trigonal structure. A brief summary of crystal structure data is given below in Table 1 .

In all these hosts, $\mathrm{Co}^{2+}$ ions occupy octahedral positions formed by oxygen ions. Their absorption spectra are typical for 6-fold coordinated $\mathrm{Co}^{2+}$ ion and have been studied in details by Wildner and Andrut ${ }^{23,25,26}$ using the Superposition Model and other empirical approaches. For the $\mathrm{Li}_{2} \mathrm{Co}_{3}\left(\mathrm{SeO}_{3}\right)_{4}$ system, the cluster for the summation over $\mathrm{i}$ in Eq.(6) of our ECM calculations consists of 8,173 ions $\left(1,183 \mathrm{Co}^{2+}, 769 \mathrm{Li}^{+}, 4,667 \mathrm{O}^{2-}\right.$ and $1,554 \mathrm{Se}^{4+}$ ions at the cut-off radial distance of $28.995 \AA)$ and 8,177 ions $\left(1,185 \mathrm{Co}^{2+}, 775 \mathrm{Li}^{+}, 4,665 \mathrm{O}^{2-}\right.$ and 1,552 $\mathrm{Se}^{4+}$ ions at the cut-off radial distance of $28.999 \AA$ ) for site I and site II, respectively. For the two kieserite systems, the cluster consists of 53,385 ions $\left(5,923 \mathrm{Co}^{2+}, 11,856 \mathrm{H}^{-}, 29,670 \mathrm{O}^{2-}\right.$ and $5,936 \mathrm{~S}^{6+}$ ions at the cut-off radial distance of $\left.49.999 \AA\right)$ and 49,109 ions $\left(5,461 \mathrm{Co}^{2+}\right.$, 
$10,890 \mathrm{H}^{-}, 27,288 \mathrm{O}^{2-}$ and $5,470 \mathrm{Se}^{6+}$ ions at the cut-off radial distance of $49.999 \AA$ ) for the $\mathrm{CoSO}_{4} \cdot \mathrm{H}_{2} \mathrm{O}$ and $\mathrm{CoSeO}_{4} \cdot \mathrm{H}_{2} \mathrm{O}$, respectively. For the brucite system, the cluster consists of 46,561 ions $\left(9,271 \mathrm{Co}^{2+}, 18,642 \mathrm{H}^{-}\right.$and $18,648 \mathrm{O}^{2-}$ ions at the cut-off radial distance of $44,993 \AA)$ and 64,803 ions $\left(12,957 \mathrm{Co}^{2+}, 25,932 \mathrm{H}^{-}\right.$and $25,914 \mathrm{O}^{2-}$ ions at the cut-off radial distance of $49.995 \AA$ ) for the temperatures $270 \mathrm{~K}$ and $90 \mathrm{~K}$, respectively. There are more ions included in the cluster for the temperature of $90 \mathrm{~K}$ system than that of the $270 \mathrm{~K}$ system because the cut-off radial distances for those two cases are different in order to maintain the site-symmetry of the CF experienced by the central $\mathrm{Co}^{2+}$ ion. On the other hand, the summation over i in Eq.(7) for the short-range exchange contribution merely runs through the 6 nearest oxygen ligands in all of those oxide crystal lattices in this study because the overlap integrals with the ions from the second and further coordination spheres are negligible. 
Table 1. Crystal structure data for $\mathrm{Li}_{2} \mathrm{Co}_{3}\left(\mathrm{SeO}_{3}\right)_{4}, \mathrm{CoSO}_{4} \cdot \mathrm{H}_{2} \mathrm{O}, \mathrm{CoSeO}_{4} \cdot \mathrm{H}_{2} \mathrm{O}, \mathrm{Co}(\mathrm{OH})_{2}$ crystals

\begin{tabular}{|c|c|c|c|c|c|}
\hline $\begin{array}{l}\text { Compound } \\
\text { (crystal type) }\end{array}$ & $\begin{array}{l}\text { Space } \\
\text { group }\end{array}$ & $\begin{array}{c}\text { Lattice } \\
\text { constants } \\
a, b, c(\text { in } \AA)\end{array}$ & $\begin{array}{l}\text { Unit cell angles } \\
\alpha, \beta, \gamma \text { (degrees) }\end{array}$ & $\begin{array}{l}\text { Number of } \\
\text { formula units } \\
\text { per unit cell }\end{array}$ & Reference \\
\hline $\mathrm{Li}_{2} \mathrm{Co}_{3}\left(\mathrm{SeO}_{3}\right)_{4}$ & $\mathrm{P} 2_{1} / \mathrm{c}$ & $\begin{array}{c}8.095,9.236 \\
7.781\end{array}$ & $90,115.76,90$ & 2 & [23] \\
\hline $\begin{array}{c}\mathrm{CoSO}_{4} \cdot \mathrm{H}_{2} \mathrm{O} \\
\text { (kieserite) }\end{array}$ & $\mathrm{C} 2 / \mathrm{c}$ & $\begin{array}{c}6.960,7.586 \\
7.621\end{array}$ & $90,118.56,90$ & 4 & {$[24]$} \\
\hline $\begin{array}{c}\mathrm{CoSeO}_{4} \cdot \mathrm{H}_{2} \mathrm{O} \\
\text { (kieserite) }\end{array}$ & $\mathrm{C} 2 / \mathrm{c}$ & $\begin{array}{c}\text { 7.091, 7.986, } \\
7.713\end{array}$ & $90,118.50,90$ & & [41] \\
\hline $\begin{array}{c}\mathrm{Co}(\mathrm{OH})_{2} \\
\text { (brucite at } 270 \mathrm{~K})\end{array}$ & $\mathrm{P} \overline{3} \mathrm{~m} 1$ & $\begin{array}{c}3.186,3.186, \\
4.653\end{array}$ & 20 & 1 & {$[42]$} \\
\hline $\begin{array}{c}\mathrm{Co}(\mathrm{OH})_{2} \\
\text { (brucite at } 90 \mathrm{~K})\end{array}$ & $\mathrm{P} \overline{3} \mathrm{~m} 1$ & $\begin{array}{c}3.179,3.179, \\
4.621\end{array}$ & 120 & 1 & {$[*]$} \\
\hline
\end{tabular}

$\left.{ }^{[*}\right]$ X-ray data from private communication with Prof. Manfred Wildner (2007).

\section{Results of CFP and energy levels calculations for all crystals}

Calculations of CFP's were performed using the ECM equations from Section 2.2. The overlap integrals between $\mathrm{Co}^{2+}$ and $\mathrm{O}^{2-}$ ions, which are needed to evaluate the exchange charge contribution, were calculated using the radial parts of the $\mathrm{Co}^{2+}$ and $\mathrm{O}^{2-}$ wave functions given in Ref. 43. For modeling the CFP's distance behavior, the interionic distances in all studied crystals were varied from $0.90 R_{0}$ to $1.10 R_{0}$ with a step of 0.01 ( $R_{0}$ stands for an equilibrium interionic distance at normal conditions). Such an approach allows for taking into account pressure effects and effects of thermal expansion. So, the 21 set of CFP's was obtained and used for a further analysis. The fitting parameter $G$ was determined by matching the calculated and experimentally observed $\mathrm{Co}^{2+}$ absorption bands, when the interionic separation is $R_{0}$ ). The results of the energy calculations (for the equilibrium interionic distances in all considered crystals), which include the free-ion Hamiltonian ${ }^{2-4,}{ }^{20}$ (with 
Racah's parameters B and C for electrostatic interaction and other minor interactions like spin-orbit interaction being neglected, i.e. the parameter $\zeta=0$ ) and the crystal field Hamiltonian $^{1-4,9,20}$ (with the CF parameters $B_{\mathrm{kp}}$ ), are shown in Tables 2-4, in comparison with corresponding experimental data. Only the spin-quartet levels (which determine the main appearance of the absorption spectra) are given in the Tables (the complete energy level schemes are available from the authors upon request). Since the reported absorption bands are broad, we have fitted positions of the calculated barycenters of groups of energy levels arising from the orbital triplets to the barycenters of the observed bands.

Table 2. Calculated energy levels $\left(\right.$ in $\left.\mathrm{cm}^{-1}\right)$ of $\mathrm{Co}^{2+}$ in sites I and II of $\mathrm{Li}_{2} \mathrm{Co}_{3}\left(\mathrm{SeO}_{3}\right)_{4}$ with the Racah parameters $B=805 \mathrm{~cm}^{-1}$ and $C=3630 \mathrm{~cm}^{-1}$.

\begin{tabular}{|c|c|c|c|c|c|}
\hline & \multicolumn{3}{|c|}{ Site I } & \multicolumn{3}{c|}{ Site II } \\
\hline & $\begin{array}{c}\text { Calc. (this } \\
\text { work) }\end{array}$ & Calc. $^{23}$ & $\begin{array}{c}\text { Calc. (this } \\
\text { work) }\end{array}$ & Calc. $^{23}$ & Exp. $^{23}$ \\
\hline \multirow{4}{*}{${ }^{4} \mathrm{~T}_{1 \mathrm{~g}}\left({ }^{4} \mathrm{~F}\right)$} & 0 & 0 & 0 & 0 & \\
& 641 & 520 & 1595 & 857 & 0 \\
& 1454 & 788 & 2020 & 1657 & \\
\hline \multirow{3}{*}{${ }^{4} \mathrm{~T}_{2 \mathrm{~g}}$} & 5942 & 6982 & 4513 & 6605 & 5850 \\
& 6940 & 7600 & 7055 & 7201 & 7550 \\
\hline${ }^{4} \mathrm{~A}_{2 \mathrm{~g}}$ & 13372 & 14818 & 12058 & 13848 & 13800 \\
\hline & 16926 & 17768 & 15819 & 16025 & 16030 \\
${ }^{4} \mathrm{~T}_{1 \mathrm{~g}}\left({ }^{4} \mathrm{P}\right)$ & 18553 & 18676 & 17950 & 18536 & 18700 \\
& 21952 & 20297 & 22460 & 20905 & 20750 \\
\hline
\end{tabular}


Table 3. Calculated energy levels (in $\mathrm{cm}^{-1}$ ) of $\mathrm{Co}^{2+}$ in $\mathrm{CoSO}_{4} \cdot \mathrm{H}_{2} \mathrm{O}$ (with $B=856 \mathrm{~cm}^{-1}$ and $C=$ $3580 \mathrm{~cm}^{-1}$ ) and $\mathrm{CoSeO}_{4} \cdot \mathrm{H}_{2} \mathrm{O}$ (with $B=841 \mathrm{~cm}^{-1}$ and $C=3490 \mathrm{~cm}^{-1}$ )

\begin{tabular}{|c|c|c|c|c|c|c|}
\hline & \multicolumn{3}{|c|}{$\mathrm{CoSO}_{4} \cdot \mathrm{H}_{2} \mathrm{O}$} & \multicolumn{3}{c|}{$\mathrm{CoSeO}_{4} \cdot \mathrm{H}_{2} \mathrm{O}$} \\
\hline & $\begin{array}{c}\text { Calc. (this } \\
\text { work) }\end{array}$ & Calc. $^{25}$ & Exp. $^{25}$ & $\begin{array}{c}\text { Calc. (this } \\
\text { work) }\end{array}$ & Calc. $^{25}$ & Exp. $^{25}$ \\
\hline \multirow{2}{*}{${ }^{4} \mathrm{~T}_{1 \mathrm{~g}}\left({ }^{4} \mathrm{~F}\right)$} & 1148 & 0 & & 0 & 0 & \\
& 1407 & 618 & - & 1511 & 730 & - \\
\hline \multirow{2}{*}{${ }^{4} \mathrm{~T}_{2 \mathrm{~g}}$} & 7029 & 7182 & 7225 & 6952 & 7140 & 7200 \\
& 8397 & 7497 & 7750 & 8233 & 7477 & 7850 \\
\hline${ }^{4} \mathrm{~A}_{2 \mathrm{~g}}$ & 15739 & 15444 & 15300 & 14681 & 15311 & 15100 \\
\hline \multirow{3}{*}{} & 19116 & 18656 & 18625 & 19655 & 18338 & 18240 \\
${ }^{4} \mathrm{~T}_{1 \mathrm{~g}}\left({ }^{4} \mathrm{P}\right)$ & 20591 & 20439 & 19000 & 21185 & 20406 & 18690 \\
& 24350 & & 20500 & 25416 & & 20270 \\
\hline
\end{tabular}

Table 4. Calculated energy levels $\left(\right.$ in $\left.^{-1}\right)$ of $\mathrm{Co}^{2+}$ in $\mathrm{Co}(\mathrm{OH})_{2}$ at the temperature $\mathrm{T}$ of $290 \mathrm{~K}$ and $90 \mathrm{~K}$. See Table 7 for values of the free-ion parameters $B, C$ and $\zeta$ used in all calculations.

\begin{tabular}{|c|c|c|c|c|c|c|}
\hline & \multicolumn{3}{|c|}{$\mathrm{T}=290 \mathrm{~K}$} & \multicolumn{3}{c|}{$\mathrm{T}=90 \mathrm{~K}$} \\
\hline & $\begin{array}{c}\text { Calc. (this } \\
\text { work) }\end{array}$ & Calc. $^{26}$ & Exp. $^{26}$ & $\begin{array}{c}\text { Calc. (this } \\
\text { work) }\end{array}$ & Calc. $^{26}$ & Exp. $^{26}$ \\
\hline${ }^{4} \mathrm{~T}_{1 \mathrm{~g}}\left({ }^{4} \mathrm{~F}\right)$ & $\begin{array}{c}0 \\
218\end{array}$ & 0 & 0 & $\begin{array}{c}0 \\
28\end{array}$ & 0 & 0 \\
\hline \multirow{2}{*}{${ }^{4} \mathrm{~T}_{2 \mathrm{~g}}$} & 7852 & 8124 & 8190 & $\begin{array}{c}7791 \\
9499\end{array}$ & $\begin{array}{c}8425 \\
8797\end{array}$ & 8350 \\
\hline${ }^{4} \mathrm{~A}_{2 \mathrm{~g}}$ & 15991 & 15965 & 15850 & 15817 & 16623 & 16900 \\
\hline \multirow{2}{*}{${ }^{4} \mathrm{~T}_{1 \mathrm{~g}}\left({ }^{4} \mathrm{P}\right)$} & 18822 & 18720 & 18800 & 18680 & 19057 & 21600 \\
\hline
\end{tabular}

The calculated values of CFP and the rotational invariant ${ }^{44} \mathrm{~s}_{\mathrm{k}}$ in Wybourne convention $B_{k p}$ for the $\mathrm{Co}^{2+}$ ion in the aforementioned four oxide crystals are presented in Tables 5, 6 and 7 together with the corresponding calculations by Wildner and Andrut ${ }^{23}, 25,26$ for direct comparison. The results of the SM fitting for the present sets of CFP are also given in those tables but the detailed method of fitting will be described in the next section. 
Table 5: Comparison of calculated crystal field parameters (in Wybourne notation) and SM parameters for the $\mathrm{Co}^{2+}$ located at sites I and II in $\mathrm{Li}_{2} \mathrm{Co}_{3}\left(\mathrm{SeO}_{3}\right)_{4}$. All parameters except $\mathrm{t}_{2}$ and $\mathrm{t}_{4}$ (which are dimensionless) are expressed in units of $\mathrm{cm}^{-1}$.

\begin{tabular}{|c|c|c|c|c|c|c|}
\hline \multirow{2}{*}{ Parameter } & \multicolumn{3}{|c|}{ Site I } & \multicolumn{3}{|c|}{ Site II } \\
\hline & (a) & (b) & (c) & (a) & (b) & (c) \\
\hline $\operatorname{Im} B_{22}$ & -478.47 & 484.4 & 763.0 & -4957.8 & -3851.52 & -6128.2 \\
\hline $\operatorname{Im} B_{21}$ & 5523.60 & 2435.9 & 4246.8 & -3513.3 & -2071.61 & -3136.8 \\
\hline$B_{20}$ & 1914.00 & 2900.2 & 5735.1 & 3133.6 & 1171.1 & 2188.0 \\
\hline $\operatorname{ReB}_{21}$ & 2860.19 & 666.3 & 2004.1 & 76.8 & 283.45 & -8.5 \\
\hline $\operatorname{ReB}_{22}$ & 879.37 & 846.1 & 1562.4 & 2819.9 & -185.85 & 41.4 \\
\hline$s_{2}$ & 4075.52 & 2147.90 & 4075 & 4462.7 & 2823.22 & 4463 \\
\hline $\bar{B}_{2}$ & & 7,000 & 14,650 & & 7,000 & 13,440 \\
\hline$t_{2}$ & & 5.5 & 4.07 & & 5.5 & 4.37 \\
\hline $\operatorname{Im} B_{44}$ & 2727.99 & 2929.3 & 2542.2 & 3170.6 & 4419.35 & 3604.1 \\
\hline $\operatorname{Im} B_{43}$ & 3947.88 & 4516.9 & 4217.7 & -3773.3 & -4071.18 & -3572.9 \\
\hline $\operatorname{Im} B_{42}$ & -9294.57 & -10311.6 & -9229.2 & -4747.1 & -5496.25 & -4538.9 \\
\hline $\operatorname{Im} B_{41}$ & 1479.38 & 1066.9 & 1025.2 & 6973.6 & 8058.03 & 7030.2 \\
\hline$B_{40}$ & -3848.00 & -4647.4 & -3995.2 & -597.6 & 403.39 & -273.4 \\
\hline $\operatorname{Re}_{41}$ & -5832.56 & -6479.4 & -5940.3 & -2247.3 & -2281 & -2209.1 \\
\hline $\operatorname{ReB}_{42}$ & -342.79 & -791 & -571.5 & -3754.3 & -4392.62 & -3652.6 \\
\hline $\operatorname{ReB}_{43}$ & -3675.41 & -4253.2 & -3508.4 & -3082.8 & -3030.21 & -3188.7 \\
\hline $\operatorname{ReB}_{44}$ & -5228.41 & -5909 & -5256.4 & -4231.5 & -4909.03 & -4240.5 \\
\hline$s_{4}$ & 6565.73 & 7346.41 & 6566 & 5621.2 & 6482.56 & 5621 \\
\hline $\bar{B}_{4}$ & & 4740 & 4,092 & & 4,740 & 4,060 \\
\hline$t_{4}$ & & 3.1 & 6.20 & & 3.1 & 6.21 \\
\hline
\end{tabular}

\section{Remark:}

(a) Present calculations based on the exchange charge model.

(b) Wildner \& Andrut's calculations ${ }^{23}$ refer to the superposition model analysis with $\mathrm{R}_{\mathrm{o}}=$ $2.1115 \AA$ and their CFP have been transformed into the present coordinate frame.

(c) Superposition model fitting of present calculated values of CFP as given in column (a). 
Table 6: Comparison of calculated crystal field parameters (in Wybourne notation) and SM parameters for the $\mathrm{Co}^{2+}$ located in $\mathrm{CoSO}_{4} \cdot \mathrm{H}_{2} \mathrm{O}$ and $\mathrm{CoSeO}_{4} \cdot \mathrm{H}_{2} \mathrm{O}$. All parameters except $\mathrm{t}_{2}$ and $\mathrm{t}_{4}$ (which are dimensionless) are expressed in units of $\mathrm{cm}^{-1}$.

\begin{tabular}{|c|c|c|c|c|c|c|}
\hline \multirow{2}{*}{ Parameter } & \multicolumn{3}{|c|}{$\mathrm{CoSO}_{4} \cdot \mathrm{H}_{2} \mathrm{O}$} & \multicolumn{3}{c|}{$\mathrm{CoSeO}_{4} \cdot \mathrm{H}_{2} \mathrm{O}$} \\
\cline { 2 - 7 } & $\mathbf{( a )}$ & $\mathbf{( b )}$ & $\mathbf{( c )}$ & $\mathbf{( a )}$ & $\mathbf{( b )}$ & (c) \\
\hline$I m \mathrm{~B}_{22}$ & 3804 & {$[0]$} & 2401 & 5111 & {$[0]$} & 3655 \\
$I m \mathrm{~B}_{21}$ & -4268 & {$[0]$} & -4210 & -4405 & {$[0]$} & -4349 \\
$B_{20}$ & -4349 & -2450 & -5709 & -6395 & -2842 & -8378 \\
$R e B_{21}$ & -2465 & {$[0]$} & -3465 & -2396 & {$[0]$} & -3128 \\
$R e B_{22}$ & 2197 & {$[0]$} & 1120 & 3471 & {$[0]$} & 2574 \\
\hline$s_{2}$ & 4606 & 1096 & 4606 & 5789 & 1271 & 5789 \\
$\bar{B}_{2}$ & & & 15357 & & & 15679 \\
$t_{2}$ & & & 4.54 & & {$[0]$} & 4.49 \\
\hline$I m B_{44}$ & -4105 & {$[0]$} & -3951 & -5556 & {$[0]$} & -5336 \\
$I m B_{43}$ & 8708 & {$[0]$} & 8807 & 8022 & {$[0]$} & 8241 \\
$I m B_{42}$ & 4744 & {$[0]$} & 4598 & 5292 & {$[0]$} & 4143 \\
$I m B_{41}$ & 4524 & {$[0]$} & 4513 & 4449 & -3505 \\
$B_{40}$ & -4856 & 16506 & -5438 & -3266 & 16233 & -3899 \\
$R e B_{41}$ & 6278 & {$[0]$} & 6117 & 6266 & {$[0]$} & 6132 \\
$R e B_{42}$ & -4010 & {$[0]$} & -4095 & -4654 & {$[0]$} & -4743 \\
$R e B_{43}$ & -4458 & {$[0]$} & -4894 & -2690 & {$[0]$} & -3148 \\
$R e B_{44}$ & 6595 & 10366 & 6220 & 6465 & 10253 & 6130 \\
\hline$s_{4}$ & 7693 & 7359 & 7693 & 7577 & 7255 & 7577 \\
$\bar{B}_{4}$ & & & 4719 & & & 4764 \\
$t_{4}$ & & & 6.35 & & & 6.35 \\
\hline $\mathrm{Remark}$ & & & & & & \\
\hline
\end{tabular}

\section{Remark:}

(a) Present calculations based on the exchange charge model.

(b) Wildner's calculations ${ }^{25}$ refer to the superposition model analysis with $\mathrm{R}_{\mathrm{o}}=2.1115 \AA$.

(c) Superposition model fitting of present calculated values of CFP as given in column (a). 
Table 7: Comparison of calculated crystal field parameters (in Wybourne notation) and SM parameters for the $\mathrm{Co}^{2+}$ located at the trigonally compressed octahedral site of $\mathrm{Co}(\mathrm{OH})_{2}$ with temperatures of $290 \mathrm{~K}$ and $90 \mathrm{~K}$. The SM parameters refer to the reference ligand distance $\mathrm{R}_{\mathrm{o}}=$

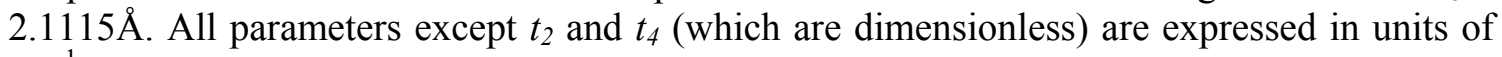
$\mathrm{cm}^{-1}$.

\begin{tabular}{|c|c|c|c|c|}
\hline & \multicolumn{2}{|c|}{ Andrut \& Wildner's SM analysis ${ }^{\mathbf{2 6}}$} & \multicolumn{2}{c|}{ Present calculations } \\
\hline Parameter & Temp=290K & Temp=90K & Temp=290K & Temp=90K \\
\hline$B$ & 825 & 830 & 825 & 830 \\
$C$ & 3550 & 3500 & 3550 & 3500 \\
\hline$B_{20}$ & -3931 & -3274 & -11673 & -11650 \\
$B_{40}$ & -8739 & -8860 & -9433 & -9808 \\
$B_{43}$ & 15010 & 15512 & 16234 & 17296 \\
\hline & & & & \\
\hline $\bar{B}_{2}$ & 4920 & 3900 & 14650 & 13127 \\
$t_{2}$ & {$[3]$} & {$[3]$} & 4.79 & 4.98 \\
\hline $\bar{B}_{4}$ & 5260 & 5320 & 5704 & 5531 \\
$t_{4}$ & {$[5]$} & {$[5]$} & 6.51 & 6.51 \\
\hline
\end{tabular}

\section{Extraction of SM parameters from CFP}

To extract the SM intrinsic parameters $\bar{B}_{k}$ and power-law exponents $t_{k}$ for $\mathrm{Co}^{2+}$ ion, the traditional approach is to carry out a least-squares fit to the sets of calculated CFP using Eqs.(2) and (3). The fitting process is notoriously difficult for low-symmetry CFP because it is a kind of non-linear fitting which may encounter many local minimas, and probably lead to divergence. Therefore, we put forward a new method for the present work consisting of the following two key steps:

Step (1) - Use the ECM to calculate the CFP for a range of uniform expansion (or contraction) in the lattice parameters of a scaling factor $f$ which gives rise to an identical fractional change (f-1) in all ionic distances. Then plot the graph (see Figures 1-4) for the rotational invariants $s_{k}$ against the scaling factor $f$ in which $s_{k}$ are related to the crystal field parameters $B_{k p}$ through the following equations:

$$
s_{k}^{2}=\frac{1}{(2 k+1)} \sum_{p}\left|B_{k p}\right|^{2},
$$

When Eq.(2) and (3) are substituted into (8), Yeung and Newman ${ }^{44}$ found that

$$
s_{k}^{2}=\frac{1}{2 k+1}\left[\bar{B}_{k}\left(R_{0}\right)\right]^{2} \sum_{i j}\left(\frac{R_{0}^{2}}{R_{i} R_{j}}\right)^{t_{k}} G_{k, 0}\left(\omega_{i j}\right)
$$


where $\omega_{i j}$ are the angles subtended by the ligands $i, j$ is at the origin (rather than heir angles referred to a specific coordinate system as noted in Eq.(2)). When the whole crystal is uniformly expanded (or contracted) by the same scaling factor $\mathrm{f}$, the new ionic distance $\mathrm{R}_{\mathrm{i}}$ ' for ion $\mathrm{i}$ is related to its original host lattice distance $\mathrm{R}_{\mathrm{i}}$ by the same factor $f=R_{i}{ }^{\prime} / R_{i}$ but all kinds of angles remain unchanged. Hence, we can easily derive from Eq.(9) that the rotational invariant $s_{k}$ also follows the same power-law dependence on $\mathrm{f}$ (like that of the intrinsic SM parameter $\bar{B}_{k}$ on the ionic distance $R_{i}$ ), i.e.

$$
s_{k} \propto f^{-t_{k}}
$$

Consequently, the graph of rotational invariants against the expansion factor $\mathrm{f}$ can help us easily determine the numerical value of the power-law exponent. It is remarked that this simple approach for the power-law formula (3) does not work for the exponential expression (4) as the term containing the scaling factor $\mathrm{f}$ could not be completely separated from individual ionic distance $R_{i}$.

Step 2 - Once the numerical values of $t_{k}$ and the polar coordinates of the ligands are known (as tabulated in Table 8(a)-(c) using the relevant crystal structure data already given in Table 1 and references therein), we could easily employ Eq.(9) to uniquely determine the numerical value of the SM intrinsic parameters $\bar{B}_{k}$ without involving any non-linear least-squares in the fitting process. The results have also been presented in Tables 5-7.

Table 8(a): Polar coordinates for the 6 nearest oxygen ligands of $\mathrm{Co}^{2+}$ as located at the distorted octahedral sites I and II in $\mathrm{Li}_{2} \mathrm{Co}_{3}\left(\mathrm{SeO}_{3}\right)_{4}$

\begin{tabular}{|c|c|c|c|c|c|}
\hline \multicolumn{3}{|c|}{ Site I ( $\mathrm{C}_{\mathrm{i}}$ symmetry) } & \multicolumn{3}{c|}{ Site II $\left(\mathrm{C}_{1}\right.$ symmetry $)$} \\
\hline $\mathrm{R} / \AA$ & $\theta /{ }^{\circ}$ & $\varphi /{ }^{\circ}$ & $\mathrm{R} / \AA$ & $\theta /{ }^{\circ}$ & $\varphi /{ }^{\circ}$ \\
\hline 2.1388 & 51.35 & 235.92 & 2.3912 & 87.58 & 327.07 \\
2.1388 & 128.65 & 55.92 & 2.1796 & 30.72 & 74.21 \\
2.0823 & 74.78 & 141.51 & 2.0323 & 109.79 & 44.30 \\
2.0823 & 105.22 & 321.51 & 2.0057 & 55.46 & 240.32 \\
2.0547 & 143.87 & 219.02 & 2.0993 & 153.38 & 241.25 \\
2.0547 & 36.13 & 39.02 & 2.1069 & 106.35 & 150.53 \\
\hline
\end{tabular}


Table 8(b): Polar coordinates for the 6 nearest oxygen ligands of $\mathrm{Co}^{2+}$ as located in $\mathrm{CoSO}_{4} \cdot \mathrm{H}_{2} \mathrm{O}$ and $\mathrm{CoSeO}_{4} \cdot \mathrm{H}_{2} \mathrm{O}$

\begin{tabular}{|c|c|c|c|c|c|}
\hline \multicolumn{3}{|c|}{$\mathrm{CoSO}_{4} \cdot \mathrm{H}_{2} \mathrm{O}$} & \multicolumn{3}{c|}{$\mathrm{CoSeO}_{4} \cdot \mathrm{H}_{2} \mathrm{O}$} \\
\hline $\mathrm{R} / \AA$ & $\theta /{ }^{\circ}$ & $\varphi /{ }^{\circ}$ & $\mathrm{R} / \AA$ & $\theta /{ }^{\circ}$ & $\varphi /{ }^{\circ}$ \\
\hline 2.0513 & 59.83 & 273.66 & 2.0498 & 74.54 & 10.36 \\
2.0513 & 120.17 & 93.66 & 2.0498 & 105.46 & 190.36 \\
2.0551 & 71.07 & 9.64 & 2.0590 & 60.41 & 277.84 \\
2.0551 & 108.93 & 189.64 & 2.0590 & 119.59 & 97.84 \\
2.1750 & 140.30 & 310.96 & 2.1938 & 140.57 & 311.33 \\
2.1750 & 39.70 & 130.96 & 2.1938 & 39.43 & 131.33 \\
\hline
\end{tabular}

Table 8(c): Polar coordinates for the 6 nearest oxygen ligands of $\mathrm{Co}^{2+}$ as located at the $\mathrm{D}_{3 \mathrm{~d}}$ site in $\mathrm{Co}(\mathrm{OH})_{2}$ with temperature of $290 \mathrm{~K}$ and $90 \mathrm{~K}$.

\begin{tabular}{|c|c|c|c|c|c|}
\hline \multicolumn{3}{|c|}{ Temp $=290 \mathrm{~K}$} & \multicolumn{3}{c|}{ Temp $=90 \mathrm{~K}$} \\
\hline $\mathrm{R} / \AA$ & $\theta /{ }^{\circ}$ & $\varphi /{ }^{\circ}$ & $\mathrm{R} / \AA$ & $\theta /{ }^{\circ}$ & $\varphi /^{\circ}$ \\
\hline 2.1156 & 119.60 & 0 & 2.106 & 119.38 & 0 \\
2.1156 & 119.60 & 120 & 2.106 & 119.38 & 120 \\
2.1156 & 119.60 & 240 & 2.106 & 119.38 & 240 \\
2.1156 & 60.40 & 60 & 2.106 & 60.62 & 60 \\
2.1156 & 60.40 & 180 & 2.106 & 60.62 & 180 \\
2.1156 & 60.40 & 300 & 2.106 & 60.62 & 300 \\
\hline
\end{tabular}

To facilitate a more direct comparison of the values of the SM parameters for $\mathrm{Co}^{2+}$ in various crystals, we have summarized the key results from the ECM calculations in Table 9. The contribution from the short-range exchange interaction has been separately calculated and presented in this table for revealing its relative importance in the overall values of the SM parameters. The other main contribution to the SM intrinsic parameters comes from the electrostatic charge distribution of the whole crystal lattice and its distance dependence strictly follows the power-law form with the exponents having the exact values of 3 and 5 for rank 2 and 4 crystal field, respectively. 
Table 9: Comparison of the superposition model intrinsic parameters $\bar{B}_{k}$ (in $\mathrm{cm}^{-1}$ ) and the power-law exponents $t_{k}$ for the $\mathrm{Co}^{2+}$ located at different oxide crystals. All the SM intrinsic parameters refer to the same reference ligand distance $R_{0}=2.1115 \AA$. Values for the shortrange exchange component of $\bar{B}_{k, S}$ and $t_{k, S}$ are given in brackets.

\begin{tabular}{|c|c|c|c|c|c|c|}
\hline \multirow{2}{*}{$\begin{array}{c}\mathrm{SM} \\
\text { Parameters }\end{array}$} & \multicolumn{2}{|c|}{$\mathrm{Li}_{2} \mathrm{Co}_{3}\left(\mathrm{SeO}_{3}\right)_{4}$} & \multicolumn{2}{|c|}{ Kieserite } & \multicolumn{2}{c|}{$\mathrm{Co}(\mathrm{OH})_{2}$} \\
\cline { 2 - 7 } & $\mathrm{Site} \mathrm{I}$ & $\mathrm{Site} \mathrm{II}$ & $\mathrm{CoSO}_{4} \cdot \mathrm{H}_{2} \mathrm{O}$ & $\mathrm{CoSeO}_{4} \cdot \mathrm{H}_{2} \mathrm{O}$ & $\mathrm{Temp}=290 \mathrm{~K}$ & $\mathrm{Temp}=90 \mathrm{~K}$ \\
\hline $\bar{B}_{2}$ & 14,650 & 13,440 & 15,360 & 15,680 & 14,650 & 13,130 \\
$\bar{B}_{2, S}$ & $(4,530)$ & $(5,710)$ & $(6,790)$ & $(6,440)$ & $(5,820)$ & $(5,780)$ \\
\hline$t_{2}$ & 4.07 & 4.37 & 4.54 & 4.49 & 4.79 & 4.98 \\
$t_{2, S}$ & $(7.02)$ & $(6.72)$ & $(6.79)$ & $(6.88)$ & $(7.51)$ & $(7.48)$ \\
\hline $\bar{B}_{4}$ & 4,090 & 4,060 & 4,720 & 4,760 & 5,700 & 5,530 \\
$\bar{B}_{4, S}$ & $(2,630)$ & $(2,600)$ & $(3,460)$ & $(3,450)$ & $(4,280)$ & $(4,240)$ \\
\hline$t_{4}$ & 6.20 & 6.21 & 6.35 & 6.35 & 6.51 & 6.51 \\
$t_{4, S}$ & $(6.89)$ & $(6.91)$ & $(6.86)$ & $(6.88)$ & $(7.03)$ & $(6.98)$ \\
\hline $\bar{B}_{2} / \bar{B}_{4}$ & 3.58 & 3.31 & 3.25 & 3.29 & 2.57 & 2.37 \\
$\bar{B}_{2, S} / \bar{B}_{4, S}$ & $(1.72)$ & $(2.20)$ & $(1.96)$ & $(1.87)$ & $(1.36)$ & $(1.36)$ \\
\hline
\end{tabular}

\section{Discussion}

From a quick glimpse of Tables 2-4, Wildner and Andrut's previous calculations ${ }^{23,25,26}$ of energy levels for $\mathrm{Co}^{2+}$ in the 4 crystal lattices seem to match better with the experimental results than compared with the results calculated from this work. However, one must note that Wildner and Andrut used a much greater number of the fitting parameters in their calculations, and so it would normally lead to an apparently better agreement. Our present ECM results were obtained from almost first-principle calculations which involved only one dimensionless adjustable parameter $\mathrm{G}$, as derived from the first absorption band. Much better results will likely be obtained if the approximation $G_{s}=G_{\sigma}=G_{\pi}=G$ is relaxed but at least three absorption bands must first be precisely detected in the experimental spectra so that the 3 dimensionless adjustable parameters $\mathrm{G}_{\mathrm{s}}, \mathrm{G}_{\sigma}$, and $\mathrm{G}_{\pi}$ of the ECM model could be uniquely determined to enhance the accuracy of our calculated results. Anyway, the energy levels 
calculated from the present ECM approach for most systems are more or less consistent with those of Wildner and Andrut's fitted results.

From Table 5, we see that our presently calculated set (shown in columns (a)) of rank 4 CFP for the $\mathrm{Co}^{2+}$ located at sites I and II in $\mathrm{Li}_{2} \mathrm{Co}_{3}\left(\mathrm{SeO}_{3}\right)_{4}$ are generally in quite good agreement with those given by Wildner and Andrut $^{23}$ as the difference between each pair of corresponding components is often less than $20 \%$, or just a few hundred $\mathrm{cm}^{-1}$. The results in column (c) reveal that the SM fitting to the presently calculated rank 4 CFP in column (a) through the use of Eqs. (9-10), and Figures 1-2 yielded two sets of highly consistent values of the SM parameters $\bar{B}_{4}$ and $t_{4}$ for the two sites I and II (with less than $1 \%$ discrepancy). The SM fitted values of individual $B_{4 p}$ parameters in column (c) also match well with those given in column (a), verifying the goodness of the superposition model in describing the angular distribution of the CFP. Although the SM intrinsic parameters $\bar{B}_{4}$ from Wildner and Andrut's work (columns (b)) do not differ much for our present SM fitted values in columns (c), yet our fitted value of the power-law exponent $t_{4}$ is twice of their value for each of the two sites. On the other hand, there are much greater discrepancies found for the rank 2 CFP when we compare the results across different methods of calculations and across the two sites. The most probable reason is that the various contributions to the rank 2 CFP tend to cancel each other and they are very sensitive to the changes in the polar coordinates of the nearest neighbour ligands. Our fitted values of the rank $2 \mathrm{SM}$ intrinsic parameter $\bar{B}_{2}$ is about twice of Wildner and Andrut's work, and this difference is very significant, so we shall later make justification for the reliability of our values.

For the CFP of $\mathrm{Co}^{2+}$ located in the two kieserite-type compounds called $\mathrm{CoSO}_{4} \cdot \mathrm{H}_{2} \mathrm{O}$ and $\mathrm{CoSeO}_{4} \cdot \mathrm{H}_{2} \mathrm{O}$, Table 6 shows that the SM fits (columns (c)) to the presently calculated CFP work quite well (especially for the rank 4 parameters). The fitted values of the rank 2 and 4 SM parameters match very well between the two kinds of crystal and it implies that the SM parameters are transferable between these two similar crystal systems. Since Wildner's ${ }^{25} \mathrm{CF}$ analysis had employed only three tetragonal CFP, namely $D q, D t$ and $D s$ which are equivalent to Wybourne's $B_{20}, B_{40}$ and $R e B_{44}$, his results should be considered as primitive findings from a pseudotetragonal approximation ${ }^{25}$. However, the overall CF strength of his rank 4 CFP (as measured by the rotational invariant $s_{4}$ ) agrees very well with our present calculations (with about $5 \%$ discrepancy) while that for the rank 2 CFP (measured by $s_{2}$ ) indicates a very 
significant difference of about 4 times. The most likely reason is because the 6 nearest oxygen ligands form a $\mathrm{CoO}_{6}$ complex with an approximate octahedral site-symmetry which gives rise mostly to the rank $4 \mathrm{CF}$. The remaining rank $2 \mathrm{CF}$, which arises from the pseudotetragonal elongation of the $\mathrm{CoO}_{6}$ octahedra, is very sensitive to the value of the power-law exponent $t_{2}$ because of the cancellation between contributions from individual ligands.

Table 7 reports the values of free ion parameters $B, C$ and $\zeta$ used in all our present calculation of the energy levels for $\mathrm{Co}^{2+}$ in $\mathrm{Co}(\mathrm{OH})_{2}$ crystal as given in Tables 2. Besides, there are calculated values of CFP and fitted values of SM parameters from our present work and Andrut and Wildner's ${ }^{26}$ work for $\mathrm{Co}^{2+}$ located at the trigonally compressed octahedral site of $\mathrm{Co}(\mathrm{OH})_{2}$ with temperatures of $290 \mathrm{~K}$ and $90 \mathrm{~K}$. While Andrut and Wildner fixed the powerlaw exponent $t_{k}$ at their electrostatic values of 3 and 5 for rank 2 and 4 crystal field, respectively, our present findings of $t_{2}=4.79$ to 4.98 and $t_{4}=6.41$ indicate that the electrostatic model is not a very good approximation. On the other hand, the values of the rank $4 \mathrm{SM}$ intrinsic parameter $\bar{B}_{4}$ from their work and our present work do agree fairly well (with about $10 \%$ discrepancy), but the rank $2 \mathrm{SM}$ intrinsic parameter $\bar{B}_{2}$ is very significantly different, by nearly 3 times. From Table $8(\mathrm{c})$, we note that both the radial distance $\mathrm{R}$ and azimuthal angle $\varphi$ of all the 6 ligands follow the perfect octahedral symmetry, but the polar angle $\theta$ deviates slightly from the perfect octahedral values of $\cos ^{-1}(1 / \sqrt{3})=54.74^{\circ}$ and $125.26^{\circ}$. Since the non-cubic configuration of the nearest neighbour oxygen ions will give rise to the rank $2 \mathrm{CF}$ as predicted by the SM, so the value of this kind of calculations for the rank 2 CF will again be strongly dependent on the accurate value of the power-law exponent $t_{2}$ because of the cancellation between contributions from individual ligands.

Table 9 reports a summary of the SM parameters $\bar{B}_{k}$ (all at the same reference ligand distance of $\mathrm{R}_{\mathrm{o}}=2.1115 \AA$ ) and $t_{k}$ for $\mathrm{Co}^{2+}$ located in 6 different host systems which all contain oxygen as their key ligands. Corresponding values for the short-range exchange (including covalency and overlapping) contributions (as calculated through the use of Eq.(7)) are also reported in brackets for revealing its importance as relative to the overall values. They are obtained when $\mathrm{B}_{\mathrm{kp}, \mathrm{s}}$ in Eq. (7) are put into the LHS of Eq. (2) and re-label the term $\bar{B}_{k}$ as $\bar{B}_{k, S}$ with the suffix $\mathrm{S}$ being added to remind us that it comes from the short-range exchange contribution. 
This Table 9 shows that while the short-range exchange contribution $\bar{B}_{k, S}$ (described by the second term in Eq. (5)) account for about $60 \%$ of the rank $4 \mathrm{CF}$, they are significantly less important in the rank $2 \mathrm{CF}$, as the latter is predominated by the electrostatic contribution $\bar{B}_{k, q}$ which can be taken as the difference between $\bar{B}_{k}$ and $\bar{B}_{k, S}$. This way of analysis is also consistent with findings given in the last two rows of Table 7 in which the ratio $\bar{B}_{2} / \bar{B}_{4}$ between the rank 2 and rank 4 SM intrinsic parameters varies from 2.4 to 3.6 whereas the corresponding ratio for the short-range exchange contribution only is substantially reduced to $1.4-2.2$. With some simple arithmetic subtractions, we can easily see that the electrostatic contributions $\bar{B}_{k, q}$ are in fact very similar in values across the six host systems (except that for $\bar{B}_{2, q}$ in site $\mathrm{I}$ of $\left.\mathrm{Li}_{2} \mathrm{Co}_{3}\left(\mathrm{SeO}_{3}\right)_{4}\right)$. On the other hand, the values of $\bar{B}_{k, S}$ do vary across the 3 types of systems, leading to some variations in the overall values of $\bar{B}_{k}$. Hence, $\bar{B}_{k, S}$ or the strengths of the short-range exchange effects are more sensitive to the presence of other ions in the host crystal and so their values are not directly transferable across crystals. Besides, the overall values of $t_{2}$ and $t_{4}$ are significantly greater than 3 and 5 , respectively as predicted by the point charge model. The extent of deviation depends on the relative values between the short-range exchange contribution $\bar{B}_{k, S}$ and the electrostatic contribution $\bar{B}_{k, q}$. The former contribution tend to raise the values of $t_{k}$ because the short-range exchange contribution $\bar{B}_{k, S}$ also closely follow the power-law form of distance dependence as shown in Figures 3 and 4. The corresponding values of the power-law exponent are lying between 6.7 to 7.5 for both rank 2 and rank 4 CF as given in Table 9. Furthermore, our present sets of $\bar{B}_{k}$ values for $\mathrm{Co}^{2+}$ actually are highly consistent with the values of $\bar{B}_{2}=12,600 \pm 1,600 \mathrm{~cm}^{-1}$ (assuming $t_{2}=3.5$ \pm 0.5 ) and $\bar{B}_{4}=4,770 \mathrm{~cm}^{-1}$ as obtained by Newman et $\mathrm{al}^{14}$ in their SM analysis of $\mathrm{Fe}^{2+}$ in a garnet host with oxygen ligands. Our present results also match well with the value of $\bar{B}_{2}=$ $14,100 \mathrm{~cm}^{-1}$ (with $t_{2}=3$ ) but are significantly lower than the value of $\bar{B}_{4}=7,900 \mathrm{~cm}^{-1}$ (with $\left.t_{4}=8.1\right)$ of which they were derived by Chang et $\mathrm{al}^{22}$ from the direct fitting of the SM intrinsic parameters to the energy level splittings for the two low-lying states (i.e. ${ }^{4} \mathrm{~A}_{2}$ and ${ }^{2} \mathrm{E}$ ) of $\mathrm{Cr}^{3+}$ doped at the $\mathrm{Nb}$ sites in $\mathrm{LiNbO}_{3}$ crystal. As clearly remarked by Chang et al, their results may contain quite significant uncertainty because of the large uncertainty about the local distortion of ionic positions around the $\mathrm{Cr}^{3+}$ ion as induced by the charge mismatch in substituting $\mathrm{Cr}^{3+}$ ions for $\mathrm{Nb}^{5+}$ ions. 
Finally, Figures 1-4 show the distance dependencies of the rotational invariants calculated in the present paper (marked by various symbols). The curves, which are calculated from the aforementioned fitting procedures through the use of Eqs. (9) and (10), clearly reveal that both the short-range exchange contribution $\bar{B}_{k, S}$ and the overall SM intrinsic parameters $\bar{B}_{k}$ do closely follow the power-law form of distance dependence. Even though both the short-range exchange contribution and the long-range electrostatic contribution follow the power-law form of distance dependence (with different values for $t_{k}$ ), the goodness of single power-law fits shown in Figures 1 and 2 confirms Newman and $\mathrm{Ng}^{7} \mathrm{~s}^{7}$ comment of no obvious phenomenological advantage to apply the alternative two-power law formula for the distance dependence of $\bar{B}_{k}(R)$ as proposed by Levin and Cherepanov ${ }^{18}$. However, we have attempted some fittings using the alternative exponential form (given in Eq. (4)) of distance-dependence for the SM intrinsic parameters. Even though this alternative form also works quite well for a short range of distances ( $\pm 10 \%$ of the mean ligand distance), some noticeable discrepancies are found at the two extremes of each fitted curve.

\section{Conclusion}

For the first time, two independent models of crystal field - the exchange charge and superposition models - have been linked together. The basic idea of our approach was to use the explicit expressions for the CFP in the ECM framework for numerical calculations of the CFP values and CF invariants for different inter-ionic distances. The main aim of such an approach is to employ the calculated sets of CFP to extract the SM parameters from the distance dependence of the calculated CF invariants, using a set of newly constructed procedures which are very simple and independent of the coordinate frames used in the calculations of the CFP's. This new method of calculating the SM parameters from the distance dependence of the CF invariants (calculated using ECM and crystal structure data) can be easily applied in a straightforward manner to other crystals, both doped and/or selfactivated. The traditional way of fitting the SM parameters to the experimental CF parameters does not work for the $3 \mathrm{~d}$ ion in low-symmetry sites because there are usually insufficient number of energy levels observed for determining all the CF parameters and the free-ion parameters. The ECM calculations enable us to determine all the SM parameters with very few spectroscopic data and so the present approach has its definite advantage. 
The numerical values of SM parameters $\bar{B}_{k}$ and $t_{k}$ for $\mathrm{Co}^{2+}$ in the six oxide crystals of $\mathrm{Li}_{2} \mathrm{Co}_{3}\left(\mathrm{SeO}_{3}\right)_{4}, \mathrm{CoSO}_{4} \cdot \mathrm{H}_{2} \mathrm{O}, \mathrm{CoSeO}_{4} \cdot \mathrm{H}_{2} \mathrm{O}$, and $\mathrm{Co}(\mathrm{OH})_{2}$ have been found to be around $13,000-16,000 \mathrm{~cm}^{-1}$ for $\bar{B}_{2}, 4,100-5,700 \mathrm{~cm}^{-1}$ for $\bar{B}_{4}, 4.1-5.0$ for $t_{2}$ and $6.2-6.5$ for $t_{4}$.

While the values of the rank $4 \mathrm{SM}$ intrinsic parameter $\bar{B}_{4}$ are in agreement with those found in the literature, a substantial difference is found for the rank 2 one. Our present results should be more reliable because the power-law exponents $t_{k}$ have been properly determined (instead of using the electrostatic value of $\mathrm{k}+1$ ), and there is additional no uncertainty about the ligand polar positions as arisen from the doping of a transition-metal ion in a charge mismatch host which will then induce local distortions around that impurity ion.

In summary, the significance of the present work is three-folded: (1) The SM is confirmed by the ECM calculations to be very good for empirical modeling of the CF parameters in the 4 oxide crystal lattices. (2) A simple method has been devised to determine the SM intrinsic parameters and power-law exponents from the ECM calculations in low-symmetry CF where many coordinated dependent CF parameters (up to 14 in total for each $3 \mathrm{~d}$ ion) are notoriously difficult for processing and for comparison across different systems. (3) It is the first time that a reliable range of values for SM intrinsic parameters and power-law exponents are determined for $\mathrm{Co}^{2+}$ in pure undistorted host lattice of 4 different oxide crystals. Our present ranges of values for the SM parameters $\bar{B}_{k}$ and $t_{k}$ will provide some reliable information and very useful initial guidance in future use of the superposition model for many different purposes such as prediction of the spectroscopic and EPR spectra ${ }^{20-22,23,26}$, proper analysis of the strain-induced zero field splittings ${ }^{19}$ and estimation of the local distortions induced by the doping of the $3 \mathrm{~d}^{\mathrm{n}}$ ion in certain host lattices ${ }^{12,16}$.

\section{Acknowledgement}

Prof. Manfred Wildner is thanked for providing some of his unpublished X-ray data for $\mathrm{Co}(\mathrm{OH})_{2}$ at $90 \mathrm{~K}$.

\section{References}

1 H. Bethe, Ann. Phys. 3, 133 (1929). 
2 S. Sugano, Y. Tanabe, and H. Kamimura, Multiplets of Transition-Metal Ions in Crystals (Academic Press, New York, 1970).

3 C.J. Ballhausen, Introduction to Ligand Field Theory (McGrow-Hill, New York, 1962).

${ }^{4}$ B.G. Wybourne, Spectroscopic Properties of Rare Earth Ions (Interscience, New York, 1965).

5 F. A. Cotton, Chemical Applications of Group Theory (John Wiley, New York, 1990).

6 B. S. Tsukerblat, Group Theory in Chemistry and Spectroscopy (Academic Press, London, 1994).

7 D.J. Newman, B. Ng, Rep. Progr. Phys. 52, 699 (1989).

8 B.Z. Malkin, in: A.A. Kaplyanskii, B.M. Macfarlane (Eds.), Spectroscopy of solids containing rare-earth ions, North-Holland, Amsterdam, 1987, pp. 33-50.

9 D.J. Newman and B. Ng (Eds.), Crystal Field Handbook (Cambridge, U.K.: Cambridge University Press, 2000).

${ }^{10}$ Y.Y. Yeung and M.F. Reid, J. Less Common Metals 148, 213 (1989).

${ }^{11}$ D.J. Newman and W. Urban, Adv. Phys. 24, 793 (1975).

${ }^{12}$ Y.Y. Yeung, J. Phys. C: Solid State Phys. 21, 2453 (1988).

${ }^{13}$ Y.Y. Yeung, J. Phys.: Condens. Matter 4, 9741 (1992).

${ }^{14}$ D.J. Newman, D.C. Price and W.A. Runciman, Amer. Mineral. 63, 1278 (1978).

${ }^{15}$ Y.Y. Yeung and D.J. Newman, J. Chem. Phys. 84, 4470 (1986).

${ }^{16}$ Y.Y. Yeung, J. Phys.: Condens. Matter 2, 2461 (1990).

${ }^{17}$ Y.Y. Yeung and D.J. Newman, J. Phys. C: Solid State Phys. 21, 537 (1988).

${ }^{18}$ L.I. Levin and V.I. Cherepanov, Soviet Phys.: Solid State 25, 399 (1983).

${ }^{19}$ Y.Y. Yeung and D.J. Newman, Phys. Rev. B 34, 2258 (1986).

${ }^{20}$ Y.Y. Yeung and C. Rudowicz, Computers and Chemistry 16, 207 (1992).

${ }^{21}$ Y.Y. Yeung, J. Qin, Y.M. Chang and C. Rudowicz, Phys. Chem. Minerals 21, 526 (1994).

${ }^{22}$ Y.M. Chang, T.H. Yeom, Y.Y. Yeung and C. Rudowicz, J. Phys.: Condens. Matter 5, 6221 (1993).

${ }^{23}$ M. Wildner, M. Andrut, Z. Kristallogr. 214, 216 (1999)

${ }^{24}$ M. Wildner, G. Giester, Neues Jahrbuch fuer Mineralogie. Monatshefte, 296 (1991).

${ }^{25}$ M. Wildner, Phys. Chem. Minerals 23, 489 (1996) 489.

${ }^{26}$ M. Andrut, M. Wildner, J. Phys.: Condens. Matter 13, 7353 (2001).

${ }^{27}$ A.G. Abragam, B. Bleaney, Electron Paramagnetic Resonance of Transition Ions (Oxford, Clarendon, 1970), chap.7. 
${ }^{28}$ G.A. Bogomolova, L.A. Bumagina, A.A. Kaminskii, B.Z. Malkin, Fizika Tverdogo Tela (Soviet Physics of the Solid State) 19, 1439 (1977).

${ }^{29}$ M.N. Popova, S.A. Klimin, E.P. Chukalina, R.Z. Levitin, B.V. Mill, B.Z. Malkin, E. AnticFidancev, J. Alloys Compd. 380, 84 (2004).

${ }^{30}$ M.N. Popova, E.P. Chukalina, B.Z. Malkin, A.I. Iskhakova, E. Antic-Fidancev, P. Porcher, J.P. Chaminade, Phys. Rev. B 63, 075103 (2001).

${ }^{31}$ M.N. Popova, S.A. Klimin, E.P. Chukalina, E.A. Romanov, B.Z. Malkin, E. AnticFidancev, B.V. Mill, G. Dhalenne, Phys. Rev. B 71, 024414 (2005).

${ }^{32}$ A.V. Savinkov, D.S. Irisov, B.Z. Malkin, K.R. Safiullin, H. Suzuki, M.S. Tagirov, D.A. Tayurskii, J. Phys.: Condens. Matter 18, 6337 (2006).

${ }^{33}$ C. Jousseaume, D. Vivien, A. Kahn-Harari, B.Z. Malkin, Opt. Mater. 24, 143 (2003).

${ }^{34}$ C. Rudowicz, M.G. Brik, N.M. Avram, Y.Y. Yeung, P. Gnutek, J Phys.: Condens. Matter 18, 5221 (2006).

${ }^{35}$ M.G. Brik, N.M. Avram, C.N. Avram, C. Rudowicz, Y.Y. Yeung, P. Gnutek, J. Alloys Compd. 432, (2007) 61.

${ }^{36}$ M.G. Brik, I.V. Kityk, Solid State Commun. 143, 326 (2007).

${ }^{37}$ S.I. Klokishner, B.S. Tsukerblat, O.S. Reu, A.V. Palii, S.M. Ostrovsky, Opt. Mater. 27, 1445 (2005).

${ }^{38}$ S.I. Klokishner, B.S. Tsukerblat, O.S. Reu, A.V. Palii, S.M. Ostrovsky, Chem. Phys. 316, 83 (2005).

${ }^{39}$ M.N. Popova, E.P. Chukalina, B.Z. Malkin, S.K. Saikin, Phys. Rev. B 61, 7421 (2000).

${ }^{40}$ S. Bertaina, B. Barbara, R. Giraud, B.Z. Malkin, M.V. Vanuynin, A.I. Pominov, A.L. Stolov, A.M. Tkachuk, Phys. Rev. B 74, 184421 (2006).

${ }^{41}$ G. Giester, M. Wildner, Neues Jahrbuch fuer Mineralogie. Monatshefte 135 (1992).

${ }^{42}$ F. Pertlik, Monatshefte fuer Chemie und verwandte Teile anderer Wissenschaften 130, 1083 (1999).

43 .M.V. Eremin, in: Spectroscopy of Laser Crystals, Ed. A.A. Kaplyanskii, Leningrad, Nauka, 1989, p. 30 (in Russian).

${ }^{44}$ Y.Y. Yeung and D.J. Newman, J. Chem. Phys. 82, 3747 (1985).

\section{Figure Captions}

Figure 1: distance dependence of the rank 2 rotational invariants $s_{2}$ for $\mathrm{Co}^{2+}$ in 6 oxide crystal systems. 
Figure 2: distance dependence of the rank 4 rotational invariants $s_{4}$ for $\mathrm{Co}^{2+}$ in 6 oxide crystal systems.

Figure 3: distance dependence of the short-range exchange component of the rank 2 rotational invariants for $\mathrm{Co}^{2+}$ in 6 oxide crystal systems.

Figure 4: distance dependence of the short-range exchange component of the rank 4 rotational invariants for $\mathrm{Co}^{2+}$ in 6 oxide crystal systems. 


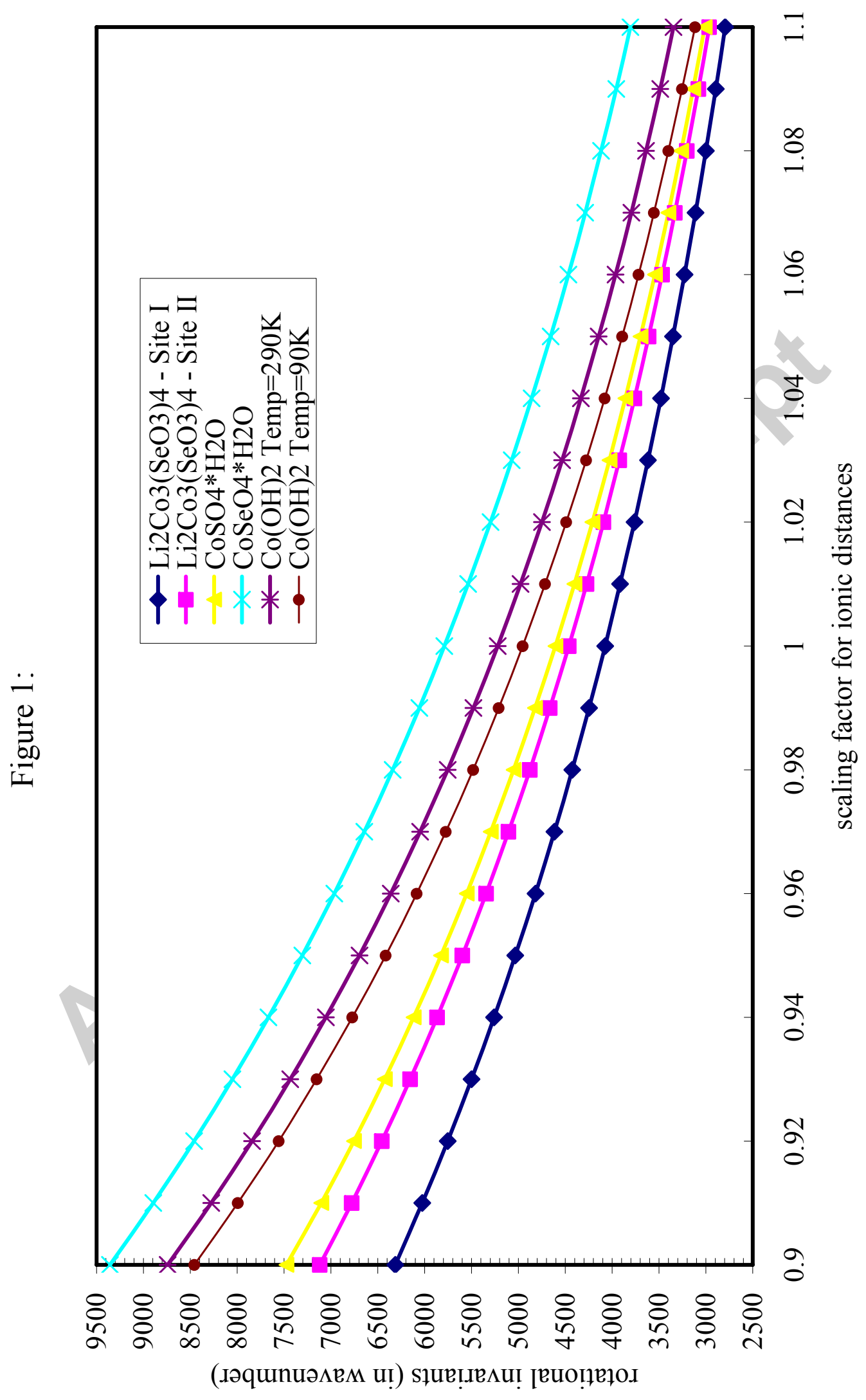




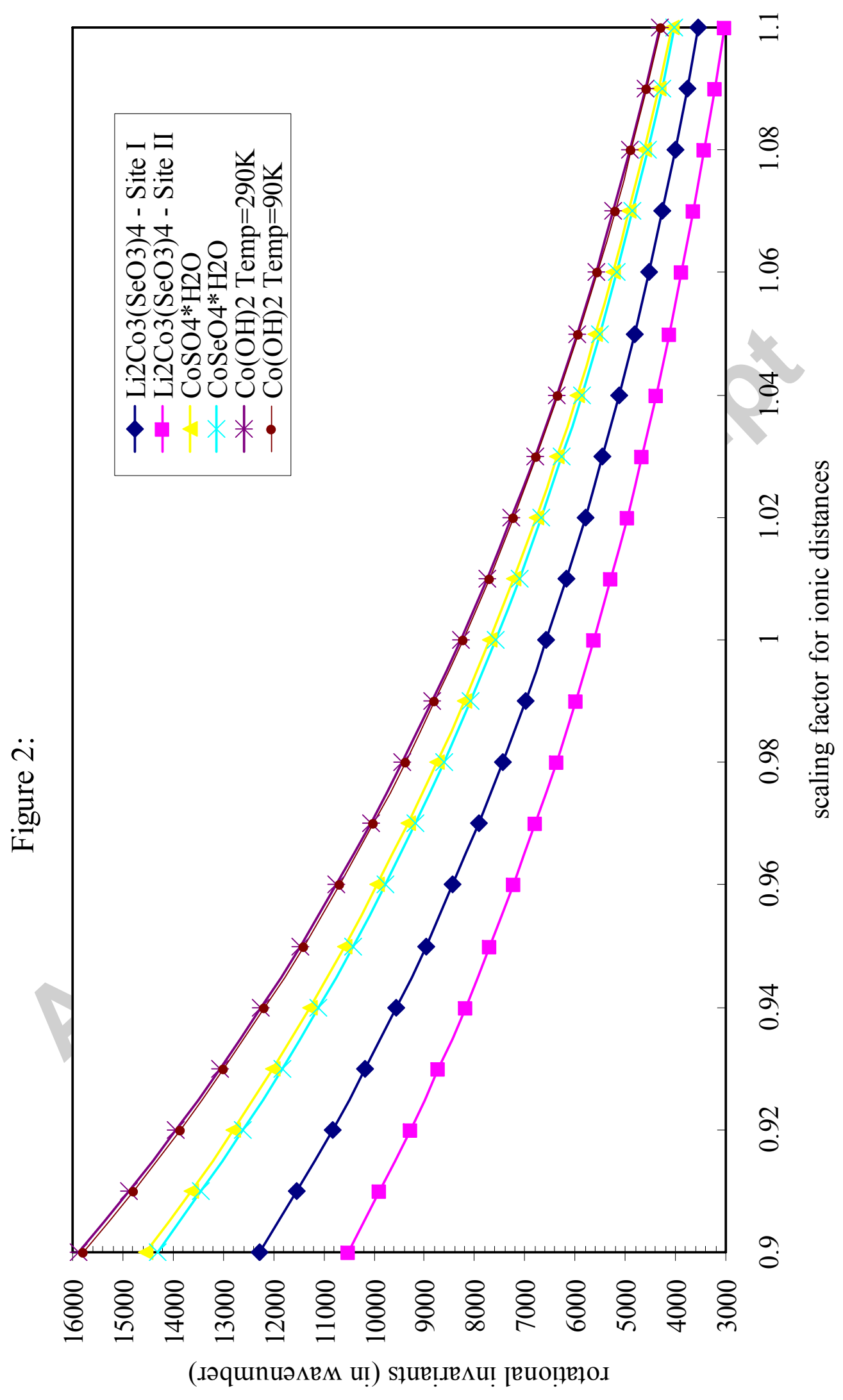




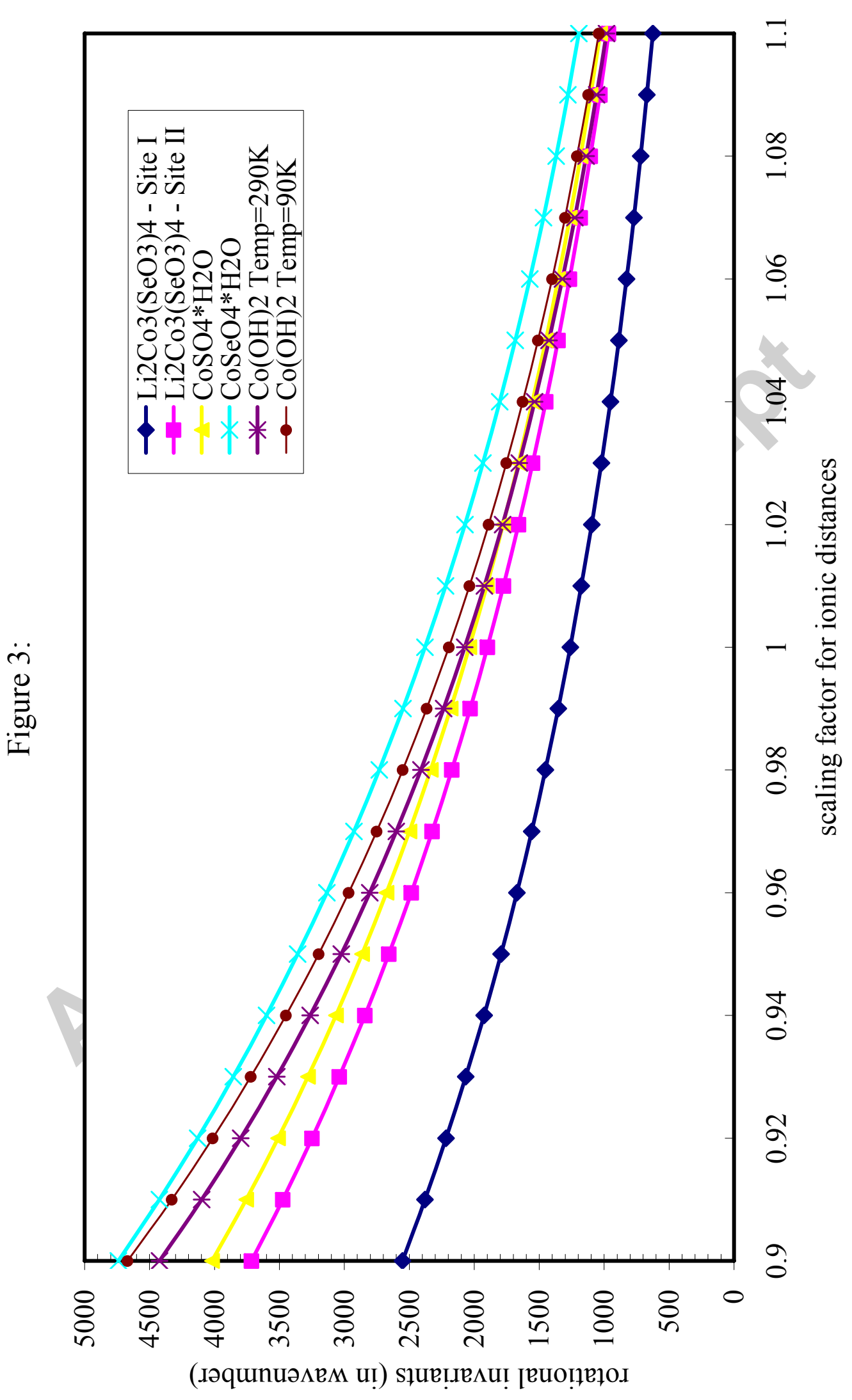




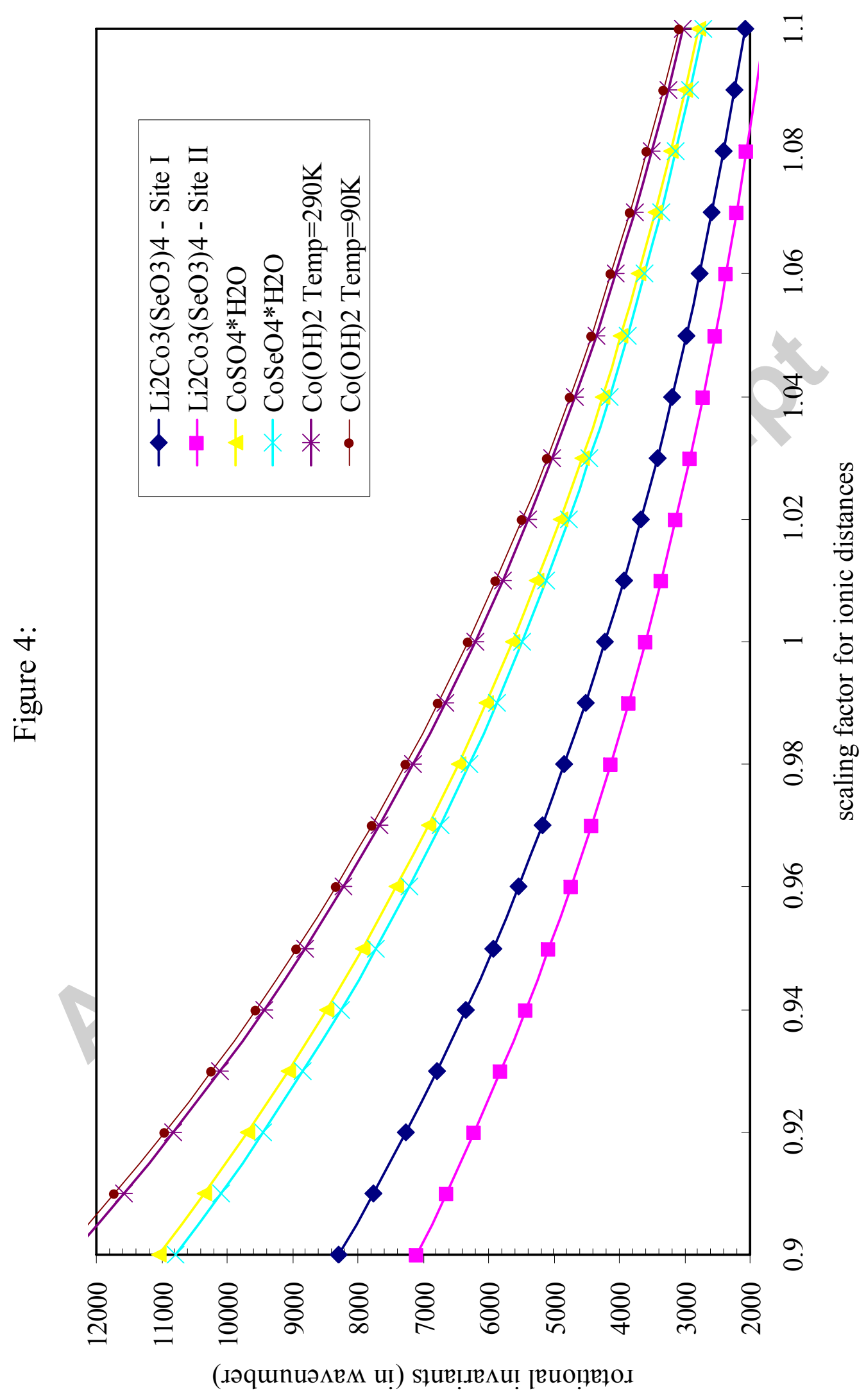

